\title{
SWITCHING OFF ANGIOGENIC SIGNALLING: CREATING CHANNELLED CONSTRUCTS FOR ADEQUATE OXYGEN DELIVERY IN TISSUE ENGINEERED CONSTRUCTS
}

\author{
Umber Cheema ${ }^{1 *}$, Tijna Alekseeva ${ }^{1}$, Ensanya A. Abou-Neel ${ }^{2}$, and Robert A. Brown ${ }^{1}$ \\ ${ }^{1}$ Tissue Repair \& Engineering Centre, Institute of Orthopaedics and Musculoskeletal Sciences, UCL Division of \\ Surgery \& Interventional Science, University College London, U.K. \\ ${ }^{2}$ Division of Biomaterials and Tissue Engineering, UCL Eastman Dental Institute, London, U.K.
}

\begin{abstract}
A major question in biomimetic tissue engineering is how much of the structure/function of native vasculature needs to be reproduced for effective tissue perfusion. $\mathrm{O}_{2}$ supplied to cells in 3D scaffolds in vitro is initially dependent upon diffusion through the scaffold and cell consumption. Low $\mathrm{O}_{2}(3 \%)$ enhances specific cell behaviours, but where $\mathrm{O}_{2}$ is critically low (pathological hypoxia) cell survival becomes compromised. We measured real-time $\mathrm{O}_{2}$ in 3D scaffolds and introduced micro-channelled architecture to controllably increase delivery of $\mathrm{O}_{2}$ to cells and switch off the hypoxic response. Simple static micro-channelling gives adequate perfusion and can be used to control cell generated hypoxia-induced signalling.
\end{abstract}

Keywords: 3D collagen scaffolds, channelled architecture, physiological hypoxia, bone marrow stromal cells, hypoxiainducible factor-I $\alpha$.

*Address for correspondence:

Umber Cheema

Tissue Repair \& Engineering Centre,

Institute of Orthopaedics and Musculoskeletal Sciences,

UCL Division of Surgery \& Interventional Science

University College London,

London, U.K.

Telephone Number: +442089095888

FAX Number: +44 2089548560

E-mail: u.cheema@ucl.ac.uk

\section{Introduction}

Within the fields of tissue engineering (TE) and tissue modelling (TM), the formation of 3D cell-seeded constructs poses problems with metabolite permeability, including $\mathrm{O}_{2}$ across longer, cell-dense matrix pathways, as delivery of factors is mainly through diffusion. Given the nature of an engineered cell scaffold, a native vasculature does not exist, potentially leading to damaging deep hypoxia with changed cell behaviour, even cell death, due to superficial cell consumption and long diffusion pathways, especially within the core of 3D constructs. Whilst synthetic polymer scaffolds have the advantage of pre-determined architecture, including porosity, which can be controlled to aid free-circulating culture media to supply cells throughout the 3D structure, they are poorly biomimetic at the meso-scale level (Rouwkema et al., 2008). Synthetic scaffolds cannot mimic the mechanical and protein properties of native materials, and therefore collagen type I is an ideal biomimetic support for engineering living tissues (Howard et al., 1996).

The dependence on $\mathrm{O}_{2}$ (as well as other nutrients) for cells and tissues is evident by the extensive vascular network throughout the mammalian body (Fraisl et al., 2009), and mimicking this vasculature is critical for successful tissue engineering. The development of a vascular network is dependent upon multiple cell types (including endothelial cells (ECs), smooth muscle cells and pericytes) and a well-orchestrated cascade of angiogenic factors regulating vessel assembly (Hirschi et al., 2002). The majority of these are under the control of the transcription factor hypoxia-inducible factor $1 \alpha$, which is a master $\mathrm{O}_{2}$ sensor, effectively initiating cells responses to low $\mathrm{O}_{2}$ environments (Semenza, 1999). Specific angiogenic factors act at precise points along the process of vessel assembly. Fibroblast growth factor 2 (FGF2) has a role in stimulating endothelial cell migration and proliferation in early vessel assembly (Beenken and Mohammadi, 2009). In addition to this, for smooth muscle cell migration and vessel wall assembly (maturation and stabilisation of the vessel) FGF2 is also critical (Kenagy et al., 1997). Vascular endothelial growth factor (VEGF) signalling is essential during the early stages of vessel assembly and this growth factor is tightly regulated. VEGF not only promotes the survival of ECs, but also acts as a chemo-attractant for ECs, implying a role in the migration and invasion of ECs (Byrne et al., 2005). In particular tip cells (i.e. the leading cells in a growing vessel sprout) are navigated along gradients of factors including VEGF (Fraisl et al., 2009). Transforming growth factor $\beta$ (TGF 
$\beta$ ) and platelet derived growth factor (PDGF-B) have also been implicated in the process of angiogenesis, however it is fair to say that there may be further factors critical to the process of angiogenesis which as of yet are unknown (Hirschi et al., 2002).

The host of factors involved in the process of angiogenesis and their tightly regulated concentrations are challenging to administer using current technologies, and we have therefore employed a technique to manipulate cells in $3 \mathrm{D}$ by the creation of low $\mathrm{O}_{2}$ environments, so that they are induced to manufacture the entire angiogenic cascade in cell-regulated concentrations (Hadjipanayi et al., 2010). Due to the lack of vasculature, gradients of $\mathrm{O}_{2}$ exist from the surface to the core of $3 \mathrm{D}$ cell-seeded constructs, and are dependent upon perfusive properties of the scaffold material and cell consumption of $\mathrm{O}_{2}$ (Cheema et al., 2008; Malda et al., 2004). By manipulation of cell density and path-length these gradients can be controlled and in some experimental cases, provide good models to test the effects of varying $\mathrm{O}_{2}$ concentration on cell behaviour. However, for the survival of a 3D TE model, an adequate, even and continuous supply of $\mathrm{O}_{2}$ is critical for viability of the core cells.

Tailoring the material properties of $3 \mathrm{D}$ tissue constructs to the $\mathrm{O}_{2}$ demand of resident cells is a challenge. This is even more so when $\mathrm{O}_{2}$ itself can be used to influence cell behaviour, and control the signals which resident cells produce. As an example, cell exposure to low physiological $\mathrm{O}_{2}$ can stimulate the upregulation of angiogenic factors, which in vivo would induce angiogenesis (Semenza, 1999). This is advantageous when building a model tissue, as along with the incorporation of ECs (the building blocks of vessels) these angiogenic proteins stimulate the production of primitive capillary networks (Simon and Keith, 2008). TE would benefit hugely if simple flow micro-channels, introduced into tissue constructs, could substitute for endothelialised tubes, until the construct integrated with the host vasculature.

$\mathrm{O}_{2}$ is a particularly good cue for angiogenic host production, as it is one of the major factors upregulating angiogenic factors in vivo, but also because employing a continuous $\mathrm{O}_{2}$ monitoring system in $3 \mathrm{D}$ allows precise readout of what cells were exposed to over 7 days (Cheema et al., 2008). In adult bone marrow, progenitors are exposed to $\mathrm{O}_{2}$ levels of $\sim 20 \mathrm{mmHg}$ (equivalent to just under $3 \%$ $\mathrm{O}_{2}$ ), this must be important in maintenance of multipotency (Fraisl et al., 2009). However the precise levels of $\mathrm{O}_{2}$ required for either inducing differentiation or inducing specific angiogenic responses remain elusive. Within the developing embryo $(\sim 25 \mathrm{mmHg})$ low levels of $\mathrm{O}_{2}$ stimulate the early mesoderm into haemangioblasts (Ramirez-Bergeron et al. 2004). Even within the vessel wall cells are exposed to different $\mathrm{O}_{2}$ levels dependent upon their location, and as such when cells are removed from their distinct location they have differing $\mathrm{O}_{2}$ requirements (Cheema et al., 2009).

Here we describe a method to produce dense cellseeded collagen constructs, where resident cells in the core up-regulate a host of angiogenic factors when exposed to low $\mathrm{O}_{2}$. This up-regulation can be effectively 'switched off' by incorporating phosphate-based glass fibres (PGFs) which dissolve over 24 hours to leave channels in the 3D construct, hence supply $\mathrm{O}_{2}$ to core cells. Previous work has shown the continuous nature of such channels created in collagen, when microbubbles were tracked through the channel lumen (Nazhat et al., 2007). We compare cell viability and regulation of angiogenic signals in constructs with/without channels. Our main hypothesis is that dissolution of PGFs will leave channels to increase $\mathrm{O}_{2}$ to core cells, and switch off angiogenic cell signalling, which is normal when cells are cultured at defined levels of physiological hypoxia. Therefore this approach provides a method to control when angiogenic signalling is switched on by cells in $3 \mathrm{D}$ (when exposed to low $\mathrm{O}_{2}$ in the core), then switched off by the introduction of channels (hence increase $\mathrm{O}_{2}$ ), and potentially leave architectural features, in which a new cell type (ECs) can be seeded to form a primitive capillary network. In this study the changing expression of angiogenic signals is used as a read-out of deep cell perfusion. We have used Human Bone Marrow derived stromal cells (HBMSCs) as the cell type studied due to the multi-potency of such cells and the clinical relevance as they are widely used in clinical practise. As well as this HBMSCs have been shown to be stem-cell like in nature and may the capability to differentiate to become cell relevant for angiogenic engineering.

\section{Materials and Methods}

\section{Cell culture}

Human bone marrow-derived stromal (or stem) cells (HBMSCs) were plated from whole blood (obtained from the operating theatre, with ethical approval from the local joint RNOH/IOMS ethics committee), as previously described (adapted from Igarashi et al., 2007). Cells were maintained in low glucose $(1000 \mathrm{mg} / \mathrm{L})$ Dulbecco's Modified Eagles Medium (DMEM, Gibco, Paisley, UK), supplemented with $20 \%$ foetal calf serum (FCS), (First Link, Wolverhampton, West Midlands, UK), 2mM glutamine and penicillin/streptomycin $(1000 \mathrm{u} / \mathrm{ml} ; 100 \mu \mathrm{g} /$ $\mathrm{ml}$, Gibco). For removal of cells from monolayer culture (all $<70 \%$ confluence), flasks were washed with $0.1 \mathrm{M}$ Phosphate Buffered Saline (PBS), and incubated with trypsin $(0.5 \%)$ for 5 minutes at $37^{\circ} \mathrm{C}$. The media specifications (i.e., low glucose and $20 \%$ FCS) were taken from published literature for optimising HBMSC growth.

\section{Collagen scaffold preparation}

$0.5 \mathrm{ml}$ of 10x Eagle's MEM solution (Gibco) was added to $4 \mathrm{ml}$ of rat-tail type I collagen $(2.04 \mathrm{mg} / \mathrm{ml}$, First Link) in $0.1 \mathrm{M}$ acetic acid and neutralised with $1 \mathrm{M} \mathrm{NaOH}$. Once neutralised, $2 \times 10^{6}$ cells were added, and gels were set for 30 minutes at $37^{\circ} \mathrm{C}$. Collagen gels were then placed on layers of blotting paper, between nylon mesh, and loaded with a $120 \mathrm{~g}$ weight for 5 minutes at room temperature, giving flat collagen sheets $(50-60 \mu \mathrm{m}$ thick) protected between 2 nylon meshes. Gels were routinely compacted by this combination of compression and blotting (with no effect to cell viability (Brown et al., 2005). Dense single sheets of collagen were then rolled to produce a tight spirally wound rod, $2.3 \mathrm{~mm}$ diameter and $21 \mathrm{~mm}$ length. 
(a)

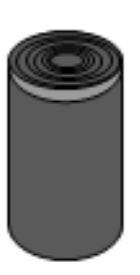

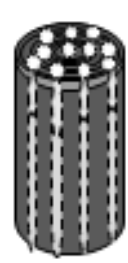

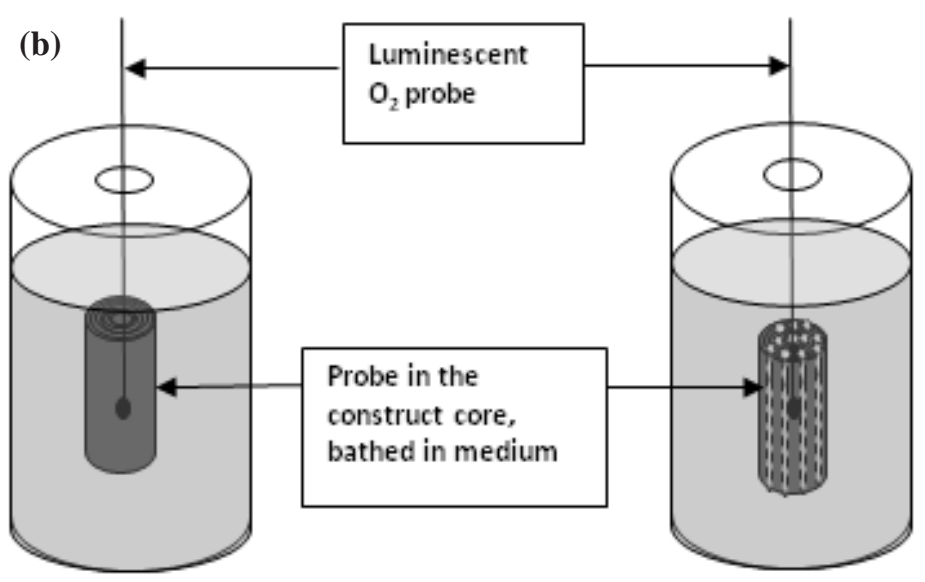

Fig. 1. (a) 3D Collagen construct schematic, with/without fibres. Over 24 hours the fibres dissolve, leaving continuous channels. (b) Diagrammatic representation of culture set-up with real-time $\mathrm{O}_{2}$ monitoring.

The collagen density after compaction was $11 \%$. Unidirectional fast degrading PGFs having composition (in mol fraction) of $0.50 \mathrm{P}_{2} \mathrm{O}_{5}-0.25 \mathrm{CaO}-0.25 \mathrm{Na}_{2} \mathrm{O}$, diameter of $\sim 40 \mu \mathrm{m}$ (inter-fibre spacing of $\sim 170 \mu \mathrm{m}$ ) were prepared and incorporated into collagen construct by laying on top of the gel prior to compression, aligned parallel to axis of spiralling (fig. 1a) as previously described (Nazhat et al., 2007).

\section{Scanning electron microscopy}

Constructs were fixed in $4 \%$ paraformaldehyde (in $0.1 \mathrm{M}$ sodium cacodylate buffer) and $1 \%$ tannic acid (in $0.05 \mathrm{M}$ sodium cacodylate buffer) both for 1 hour, followed by dehydration through an alcohol series to hexamethyldisilazane with air drying. Samples were then gold-palladium sputter-coated, and then viewed using a JEOL (Tokyo, Japan) 5500LV scanning electron microscope (SEM).

\section{Real-time $\mathrm{O}_{2}$ measurement}

Fibre-optic oxygen probes (Oxford Optronix, Oxford, UK) were inserted into the centre of the $3 \mathrm{D}$ constructs to place the measuring tip halfway along their long axis (Fig. 1b). This gave a diffusion length of $>1 \mathrm{~mm}$ (from surface to core, perpendicular to the long axis, here termed lateral diffusion). The collagen constructs are spiralled and form robust 3D structures. These were not tethered, however when a fibre-optic probe was inserted in the core, it was possible to position the probe (with an external clamp) in a pot of media, so the construct was bathed within the media (and essentially held in place by the probe running through its core). The sensor probe $(280 \mu \mathrm{m}$ diameter $)$ incorporates an oxygen sensitive luminescent probe, which is quenched in the presence of molecular oxygen so that the luminescence emission lifetime is extended longer at lower local oxygen tensions. The calibration of the probe (accurate to $0.7 \mathrm{mmHg}$ ), correlating the luminescence lifetime versus the oxygen concentration (Seddon et al., 2001), gives an exceptionally stable and calibrated response. After each experiment, the probe reading was checked in the external medium to confirm that there was no drift in the response. The fibre-optic probes were used in conjunction with an OxyLab (Oxford Optronics, Oxford, $\mathrm{UK}) \mathrm{pO} 2 \mathrm{E}^{\mathrm{TM}}$ system coupled to an analogue/digital converter (12 bit).The results were recorded on a standard laptop using Labview (National Instruments, Austin, TX, USA) and are presented as partial pressure values, i.e., $\mathrm{pO}_{2}$ in $\mathrm{mmHg}$ (e.g., $7.6 \mathrm{mmHg}$ corresponds to $1 \% \mathrm{O}_{2}$ ).

\section{Quantitative PCR}

RNA was extracted from the spiral construct, by unrolling and dissecting out the core. Total cellular RNA was isolated using the Qiagen RNeasy method (Qiagen UK, Crawley, West Sussex, UK). RNA was measured using the Nanodrop ${ }^{\mathrm{TM}}$.

First strand cDNA synthesis was performed using Amplitaq Reverse Transcriptase (Applied Biosystems, Roche, Basel, Switzerland). Total RNA (0.5 $\mu \mathrm{g}$ RNA in $40 \mu \mathrm{l}$ ) was added to $9.15 \mu \mathrm{l}$ of mastermix (dNTP, RNase inhibitor, $\mathrm{MgCl}$, Oligo DT Random primers), and heated at $70^{\circ} \mathrm{C}$ for 10 minutes. Then $2 \mu$ of Reverse Transcriptase was added to each tube and incubated at $40^{\circ} \mathrm{C}$ for 1.5 hours, followed by heating at $90^{\circ} \mathrm{C}$ for 2 minutes.

Relative quantitative PCR was performed using Applied Biosystems 7300 Real-time PCR system (Carlsbad, CA, USA), with the Taqman universal PCR Master Mix. $9 \mu \mathrm{l}$ of the cDNA, $1 \mu \mathrm{L}$ of the required gene probe (Assay IDs: 18S RNA: HS99999901_s1; VEGF: Hs00900057_m1; HIF-I $\alpha$ : HS00936366_m1; FGF2: HS00266645 $\mathrm{ml}$ ) and $10 \mu \mathrm{l}$ of Mastermix were mixed per sample for cycling and analysis in the Applied Biosystems 7300 Real-time PCR machine. The primer sequences are kept confidential by Applied Biosystems. The combined thermal cycling and amplification-specific software enabled detection of the PCR products as cycleby-cycle accumulation in a single-tube reaction.

CT (cycle threshold) values, indicating when the PCR product was amplified in a logarithmic manner, were ascertained using the Applied Biosystems software. Values for each sample were normalised to the corresponding $18 \mathrm{~S}$ RNA result according to the following equation and then values were directly compared.

$$
\frac{1}{2^{\text {(CT test }- \text { CT controlgene })}}
$$

Signalling experiments were performed independently of the cell viability, and a sample size (n) of 4 per time point and construct type were analysed. 
(a)
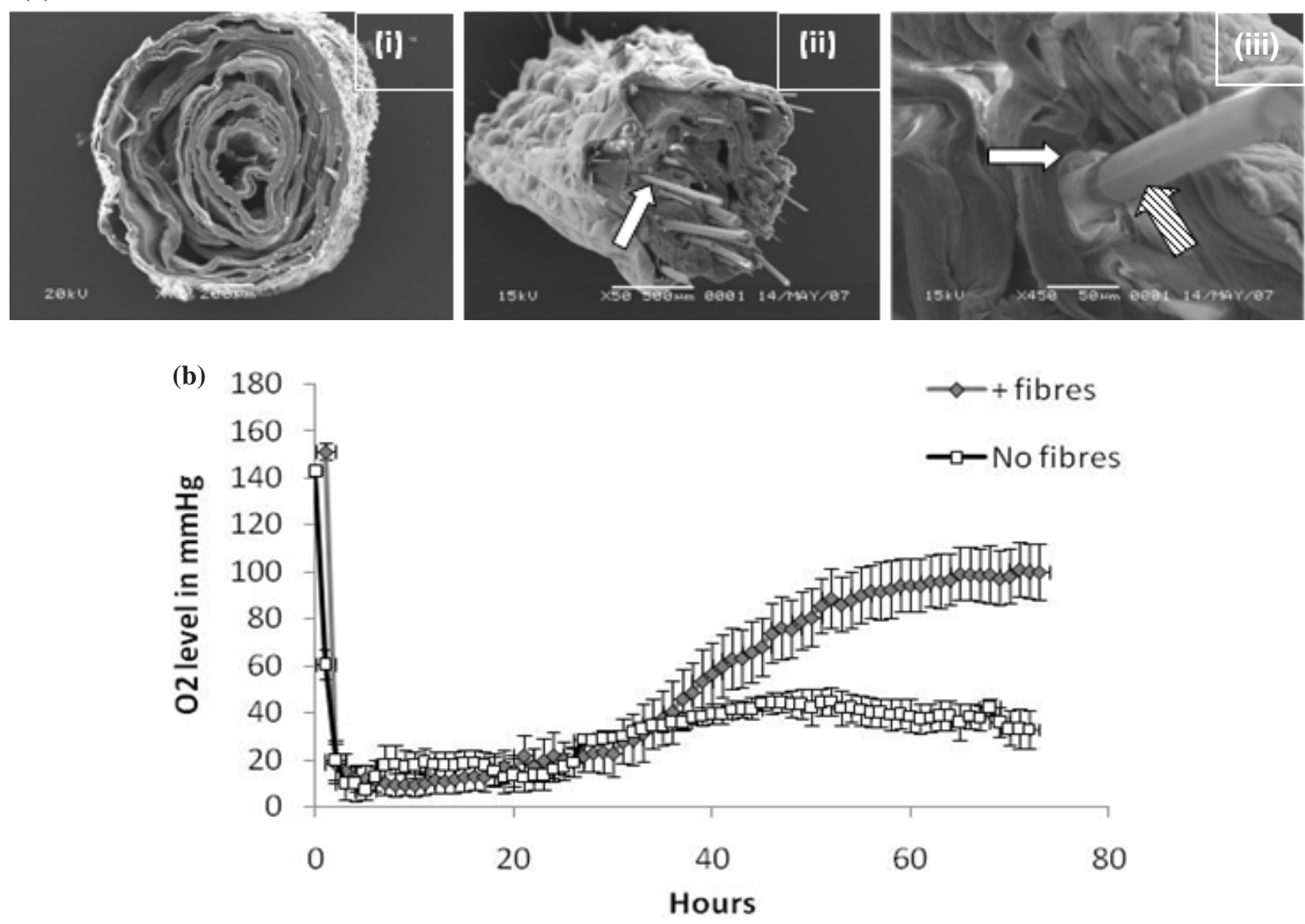

Fig. 2. (a) (i) SEM micrograph of collagen construct, (ii) with glass fibres. (iii) Construct containing dissolving glass fibres, as the fibre is gradually dissolving the channel forming is visible. Striped arrow indicates the incorporation of a PGF, and plain arrow denotes the channel wall which is left following dissolution of the fibre after 4 hours. (b) $\mathrm{O}_{2}$ levels in the core of cell-collagen constructs with/without dissolving PGFs. By 24 hours the fibres have completely dissolved, and levels of $\mathrm{O}_{2}$ increase in the core, compared to control constructs without fibres, up to 3 days.

\section{Cell viability}

Quantitative analyses were carried out with Live/Dead Reduced Biohazard Viability/Cytotoxity Kit (Molecular Probes, Invitrogen, Carlsbad, CA, USA, L-7013) according to the manufacturer's protocol. $\mathrm{SYTO}^{\circledR} 10$, a green fluorescent nucleic acid stain for live cells, and Ethidium homodimer-2, a red stain for dead cells, were used to stain constructs after which images were taken in 10 random fields within the core region using confocal microscopy (BioRad Radiance 2100, Carl Zeiss, Welwyn Garden City, UK). Live/dead nuclei were counted to ascertain percentage viability. Cell viability experiments were performed independently of the signalling, and a sample size (n) of 3.

\section{Results and Discussion}

SEM images show the collagen construct without and with embedded PGFs (Fig. 2a (i) and (ii)), with the detail of a single glass fibre gradually dissolving at 4 hours (Fig. 2a (iii)). The dissolution of glass fibres takes $24 \mathrm{~h}$, however, at $4 \mathrm{~h}$ it is possible to see some degradation of the fibre, and the channel that is gradually being created, which will be complete when the fibre fully dissolves by $24 \mathrm{~h}$. Continuous $\mathrm{O}_{2}$ plots show that levels decrease within the initial $2 \mathrm{~h}$ of culture time. These low levels $(\sim 20 \mathrm{mmHg})$ were maintained such that resident HBMSCs in the core were exposed to this physiological hypoxia for the first 24 h. There was a gradual increase in $\mathrm{O}_{2}$ from $40 \mathrm{~h}$ onwards, to $\sim 40 \mathrm{mmHg}$ (Fig. 2b), where cells were exposed to a range of $\mathrm{O}_{2}$ from between $20-40 \mathrm{mmHg}\left(2.6-5.3 \% \mathrm{O}_{2}\right)$. In constructs containing PGFs, however, an increase in core $\mathrm{O}_{2}$ tension was evident after the $24 \mathrm{~h}$ dissolution period (Fig.2b). This produced an increase in $\mathrm{O}_{2}$ to $\sim 80 \mathrm{mmHg}$ $(10.5 \%)$ and $\sim 100 \mathrm{mmHg}(13.1 \%)$ by 48 and $72 \mathrm{~h}$, respectively. The formation of channels therefore increased supply of $\mathrm{O}_{2}$ to cells within the core. The introduction of microchannel architecture into 3D collagen constructs can be easily controlled by adjusting PGF's chemistry (AbouNeel et al., 2005).

A direct comparison of HBMSC cells with pulmonary artery smooth muscle cells (PASMCs), within this system can be made where at the same cell density $\mathrm{O}_{2}$ levels dropped to well below $10 \mathrm{mmHg}$ in the core of seeded constructs (Cheema et al., 2009). The high $\mathrm{O}_{2}$ demand of PASMCs is interesting as they themselves are already part of the vascular network, whereas EC cells, the first cells 


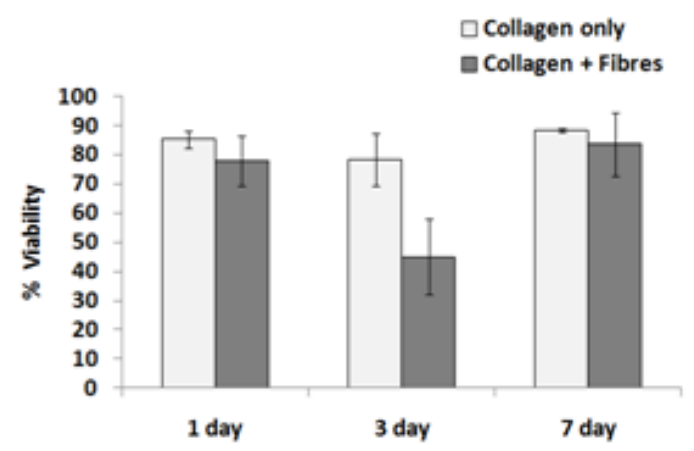

(a)

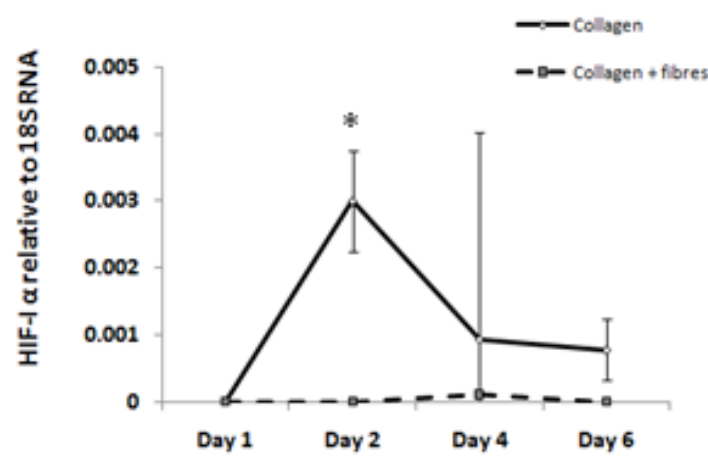

(b)

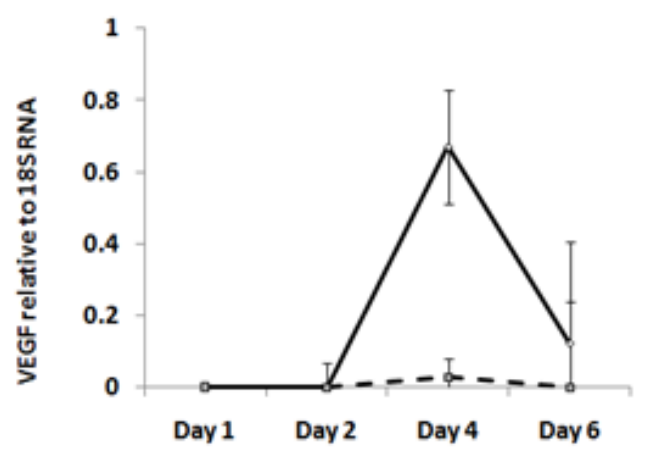

(c)

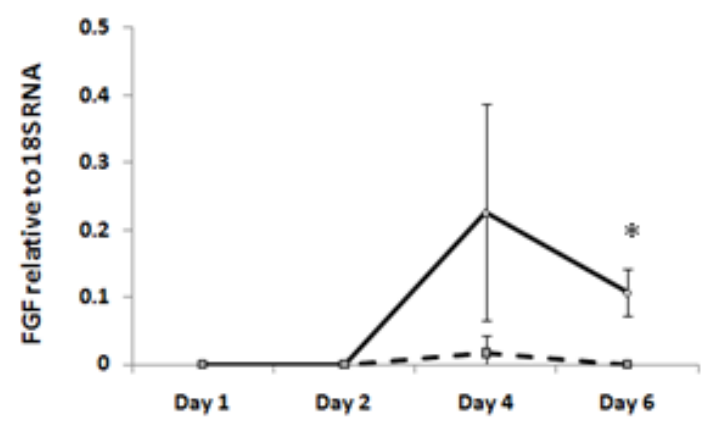

Fig. 3. (a) Viability of Human Bone-marrow derived stromal cells in $3 \mathrm{D}$ constructs with and without fibres. (b) VEGF in constructs with and without fibres. (c) HIF-I a in constructs with and without fibres. (d) FGF in constructs with and without fibres. *denotes statistically significant differences between the 2 groups using students $t$-test, $p<0.05$.

to come into contact with oxygenated blood in the vascular system have a relatively low $\mathrm{O}_{2}$ demand, and instead derive most of their energy anaerobically through glycolysis (Quintero et al., 2006). A study comparing the angiogenic factor output of these cells should provide further insight into how vascular networks can be ideally engineered in culture.

Viability of cells was established to correlate $\mathrm{O}_{2}$ exposure to cell survival. There was a decrease in cell viability in collagen/PGFs constructs by day 3 (Fig. 3a). This was due to the release of dissolution products from the glass fibres, as no comparable fall was seen without fibres. Interestingly though, this fall was noticeable not at $24 \mathrm{~h}$, but at $72 \mathrm{~h}$. We hypothesise this to be due to the fact that as it took $24 \mathrm{~h}$ for the fibres to completely dissolve, at this point there was a maximal exposure of the known dissolution products to cells in the constructs. As viability wasn't checked at $48 \mathrm{~h}$, the reading at $72 \mathrm{~h}$ is simply a late indication of the reduced viability on day 2 . The drop in viability can only be directly influenced by the dissolution of PGF fibres, as there was no comparable fall in identical cultures without the fibres. Cell death due to low $\mathrm{O}_{2}$ in collagen only was minimal. In PGF/collagen constructs and the transient nature of the reduced cell viability was seen by day 7, when all the glass products had disappeared, and viability returned to $\sim 80 \%$ (Fig. 3a). This increase in viability must have been due to an increased proliferation rate of cells in the PGF/collagen composite cultures.

Angiogenic signalling was up-regulated when cells were exposed to $20-40 \mathrm{mmHg}$ or $2.6-5.2 \% \mathrm{O}_{2}$. Peak expression of HIF-I $\alpha$ was at day 2, followed by VEGF at day 4 and FGF2 at day 6, in collagen scaffolds, in response to physiological hypoxia (Fig. 3b-d). However no significant elevation in of any of these angiogenic genes was seen in channelled collagen/PGF constructs despite cell death at day 3 (Fig. 3). This is clear evidence that hypoxia was the stimulus for angiogenesis factor expression that the presence of PGF channels prevented this stimulation.

In addition since cells in both types of constructs were exposed to $\mathrm{O}_{2}$ levels of $\sim 20 \mathrm{mmHg}$ over the initial $24 \mathrm{~h}$ of culture, it would seem that HIF-I $\alpha$ signalling is not triggered by cells in 3D by short-term exposure to this level of low $\mathrm{O}_{2}$. Rather, exposure for 24-48 $\mathrm{h}$ at this level is needed to initiate angiogenic response and, further, that the response is effectively reset or stopped by rising $\mathrm{O}_{2}$ during this time period.

Although there was a decrease in cell viability by day 3 in collagen/PGF constructs, qPCR expression data was relative to $18 \mathrm{~S}$ RNA, and so was corrected for the reduced cell numbers. HIF-I $\alpha$ is a master $\mathrm{O}_{2}$ sensor within cells, and a transcription factor for a multitude of downstream factors, including VEGF (Semenza, 1999). Consequently, without HIF-I $\alpha$ upregulation in collagen/PGF constructs, the up-regulation of VEGF was also prevented. VEGF levels were higher in collagen only constructs by day 4 , where $\mathrm{O}_{2}$ levels remained low (Fig. 3c). Hence, the upregulation of VEGF at day 4 is likely to be HIF-I $\alpha$ mediated. The upregulation kinetics of HIF-I $\alpha$ in this $3 \mathrm{D}$ system are quite different from studies looking at cells 
grown in medium, where HIF-I $\alpha$ upregulation has been measured within minutes rather than hours or days (Jewell et al., 2001). This difference is likely to be due to the differences in cell types studied and $\mathrm{O}_{2}$ exposure: whereas other studies subject cells to $\mathrm{O}_{2}$ levels from $0-0.5 \%$, we stayed within above a threshold of $2.5 \%$. The current study is specifically looking at cell behaviour in a $3 \mathrm{D}$ native matrix environment, and therefore will have some physiological advantages over studies looking at cells outside of this geometric environment. If a hypoxic response was required, i.e., to produce angiogenic signals to form a primitive vascular network, $\mathrm{O}_{2}$ levels would either need to be lower in the core (increase cell $\mathrm{O}_{2}$ consumption), or the fibres chemistry would need to be adjusted to keep core cells exposed to $20-40 \mathrm{mmHg} \mathrm{O}$ for up to $48 \mathrm{~h}$.

Levels of FGF2 were significantly higher in collagenonly constructs (Fig. 3d) by day 6. FGF2 is a more potent angiogenic factor than VEGF. As it is up-regulated through a different mechanism, it may be suggested that prolonged hypoxia was again the trigger. It can therefore be postulated that many such factors (probably much of the angiogenic cascade) will have been affected and regulated through the low $\mathrm{O}_{2}$ environment. The role of FGF2 in the process of angiogenesis is two-fold. During the formation of a vessel, the early lineage commitment of ECs is regulated by FGF2 and later on the recruitment of other mural cells (i.e., smooth muscle cells) is also regulated by FGF2 to stabilise the forming vessel (Hirschi et al., 2002).

Addition of these PGFs to create channelled architecture in 3D scaffolds is a simple method to deliver $\mathrm{O}_{2}$ to cells throughout the $3 \mathrm{D}$ structure. This study specifically targeted $\mathrm{O}_{2}$ delivery; however, other nutrients, including glucose, may also be delivered through diffusion via the same channels. Any angiogenic proteins produced will diffuse along the path of least resistance, i.e. along the channel tracks. Architectural features in 3D scaffolds can, therefore, be used to both control specific cell behaviour and aid media perfusion. It may be necessary to produce fibres with longer dissolution periods, so resident cells within the core optimally upregulate angiogenic factors, before $\mathrm{O}_{2}$ is gradually delivered. The degradation of the PGF within the construct is an active process and depends on several factors: (i) Fibre diameter; (ii) Fibre composition; (iii) Spacing between them; (iv) Flow rate of the surrounding medium into the construct (density of collagen construct). These fibres are completely degradable into ionic products (e.g., $\mathrm{Ca}, \mathrm{Na}$ and $\mathrm{PO}_{4}$ ) according to their compositions. These ions can be utilised by the body or easily eliminated by the normal physiological mechanism. Altering the chemistry or diameter of such fibres will allow introduction of the channelled architecture in a controlled, predictable manner.

\section{Conclusion}

Timed introduction of a gradual channelled architecture into $3 \mathrm{D}$ cell-seeded collagen tissue constructs results in the switching off of angiogenic signalling by resident cells, dependent upon the ambient $\mathrm{O}_{2}$ tension in the surrounding media. Therefore, simple channelling is an effective means of engineering deep cell perfusion, without the aid of media flow. By monitoring core $\mathrm{O}_{2}$ levels, and correlating them with cell viability and angiogenic gene upregulation, cell growth in 3D and specific cell signalling can be controlled and optimised. The addition of architectural features within 3D scaffolds, therefore, influences cell behaviour in terms of signalling.

\section{Acknowledgements}

Umber Cheema is a BBSRC David Phillips Fellow and is funded through this route.

\section{References}

Abou-Neel EA, Ahmed I, Blaker JJ, Bismarck A, Boccaccini AR, Lewis MP, Nazhat SN, Knowles JC (2005) Effect of iron on the surface, degradation and ion release properties of phosphate-based glass fibres. Acta Biomater 1: $553-563$.

Beenken A, Mohammadi M (2009). The FGF family: biology, pathophysiology and therapy. Nat Rev Drug Discov 8: 235-253.

Brown RA, Wiseman M, Chuo CB, Cheema U, Nazhat SN (2005) Ultrarapid engineering of biomimetic materials and tissues: Fabrication of nano- and microstructures by plastic compression. Adv Funct Mater 15: 1762-1770.

Byrne AM, Bouchier-Hayes DJ, Harmey JH. (2005) Angiogenic and cell survival functions of vascular endothelial growth factor (VEGF). J Cell Mol Med 9: 777794.

Cheema U, Brown RA, Alp B, MacRobert AJ (2008) Spatially defined oxygen gradients and VEGF expression in an engineered 3D cell model. Cell Mol Life Sci 65: 177-186.

Cheema U, Hadjipanayi E, Tamimi N, Alp B, Mudera V, Brown RA (2009) Identification of key factors in deep $\mathrm{O}-2$ cell perfusion for vascular tissue engineering. Int $\mathrm{J}$ Artif Organs 32: 318-328.

Fraisl P, Mazzone M, Schmidt T, Carmeliet P (2009) Regulation of angiogenesis by oxygen and metabolism. Dev Cell 16: 167-179.

Hadjipanayi E, Brown RA, Mudera V, Deng D, Liu W, Cheema U (2010). Controlling physiological angiogenesis by hypoxia-induced signalling. J Control Rel 146: 309317.

Hirschi KK, Skalak TC, Peirce SM, Little CD (2002) Vascular assembly in natural and engineered tissues. Ann N Y Acad Sci 961: 223-242.

Howard EW, Benton R, Ahern-Moore J, Tomasek JJ (1996) Cellular contraction of collagen lattices is inhibited by nonenzymatic glycation. Exp Cell Res 228: 132-137.

Igarashi A, Segoshi K, Sakai Y, Pan H, Kanawa M, Higashi Y, Sugiyama M, Nakamura K, Kurihara H, Yamaguchi S, Tsuji K, Kawamoto T, Kato Y (2007) Selection of common markers for bone-marrow stromal cells from various bones using real-time RT-PCR: Effects 
of passage number and donor age. Tissue Eng 13: 2405 2417.

Jewell UR, Kvietikova I, Scheid A, Bauer C, Wenger RH, Gassmann M (2001). Induction of HIF-1alpha in response to hypoxia is instantaneous. FASEB J 15: 13121314.

Kenagy RD, Hart CE, Stetler-Stevenson WG, Clowes AW (1997) Primate smooth muscle cell migration from aortic explants is mediated by endogenous platelet-derived growth factor and basic fibroblast growth factor acting through matrix metalloproteinases 2 and 9. Circulation 96 : 3555-3560.

Malda J, Rouwkema J, Martens DE, Le Comte EP, Kooy FK, Tramper J, van Blitterswijk CA, Riesle J (2004) Oxygen gradients in tissue-engineered PEGT/PBT cartilaginous constructs: measurement and modeling. Biotechnol Bioeng 86: 9-18.

Nazhat SN, Abou Neel EA, Kidane A, Ahmed I, Hope C, Kersha M, Lee PD, Stride E, Saffari N, Knowles JC, Brown RA (2007) Controlled microchannelling in dense collagen scaffolds by soluble phosphate glass fibres. Biomacromolecules 8: 543-551.

Quintero M, Colombo SL, Godfrey A, Moncada S (2006) Mitochondria as signalling organelles in the vascular endothelium. Proc Natl Acad Sci USA 103: 53795384.

Ramirez-Bergeron DL, Runge A, Dahl KD, Fehling H.J, Keller G, Simon MC (2004) Hypoxia affects mesoderm and enhances hemangioblast specification during early development. Development 131: 4623-4634. Rouwkema J, Rivron NC, van Blitterswijk CA (2008) Vascularization in tissue engineering. Trends Biotechnol 26: 434-441.

Seddon BM, Honess DJ, Vojnovic B, Tozer GM, Workman P (2001) Measurement of tumor oxygenation: In vivo comparison of a luminescence fiber-optic sensor and a polarographic electrode in the p22 tumor. Radiat Res 155: 837-846.

Semenza GL (1999) Perspectives on oxygen sensing. Cell 98: 281-284.

Simon MC, Keith B (2008) The role of oxygen availability in embryonic development and stem cell function. Nat Rev Mol Cell Biol 9: 285-296.

\section{Discussion with Reviewers}

Reviewer I: What is the long term of this study? Can the probe be used in vivo? What are the clinical implications of this model?

Authors: The long term implications for this study are two-fold. The first is focused on in vitro engineering. In $3 \mathrm{D}$ constructs (not necessarily just collagen) the formation of $\mathrm{O}_{2}$ gradients provides a means to upregulate angiogenic cascades by resident cells, in the form of hypoxia-induced signalling. The cell density can be controlled to optimise this signalling, and the addition of real-time $\mathrm{O}_{2}$ monitoring means cells behaviours can be attributed to differing $\mathrm{O}_{2}$ tensions. Once signalling is optimal (i.e. prior to any detrimental affect the hypoxia may have, i.e. enter levels of pathological hypoxia) this can be fed into the design of PGF fibres, so they dissolve at this precise time to leave continuous channels throughout the construct. The presence of angiogenic factors may then be used to introduce a further cell type, endothelial cells, to line the channel lumen, to form a base vascular network.

The second implication is in vivo, such constructs have the capacity to provide channelled architectural features along which vascular networks and neural networks can anastomose.

Real-time $\mathrm{O}_{2}$ monitoring using this system has been possible in vivo (Hadjipanayi et al., 2010) and this real time measurement of changing in vivo local $\mathrm{O}_{2}$ levels, deep inside the implant, is probably the most effective/relevant functional outcome of angiogenic engineering currently available. This provides direct readout of the integration and likely survival of constructs, making close analysis of the core $\mathrm{O}_{2}$ data particularly important.

Reviewer II: Please comment on the actual perfusion improvement for a collagen gel by introducing a channelled architecture under static conditions.

Authors: The improved delivery of $\mathrm{O}_{2}$ in a scaffold where no perfused media system is in place is interesting. It may be expected that without actual flow this delivery would be limited, with little affect on cells in the core of 3D scaffolds. In contradiction to this, we have found significant changes in cell signalling in response to the introduction of simple channels without the aid of perfusion. This finding is of interest to the broad spectrum of $3 \mathrm{D}$ scaffold engineers.

Reviewer III: The manuscript describes linear fibres aligned parallel to the axis of spiralling in the constructwould it be possible to have smaller fibres perpendicular to these fibres, to mimic, for instance, the presence of capillaries between arteries and veins? Given time, would endothelial cells line these channels?

Authors: The fibre arrangement within a 3D scaffold is of significant importance, as these channels are designed to try and mimic the vascular network within tissues. Indeed a range of fibre diameters (mimicking larger arteries and veins with smaller capillaries) would be an ideal scenario, and work in this area is currently underway. The arrangement of fibres is slightly more complex given the configuration of the 3D scaffold. By creating a dense 3D sheet of cells and collagen, we rely upon spiralling of this sheet for 3D configuration. However, this only allows relatively rigid PGF fibres to be aligned along the 'static' axis, and not the 'rolling' axis (Supplementary Fig. 1.).

Reviewer III: Does the diameter of these micro-channels correspond to those of new vessels formed during angiogenesis? Would it be possible for cells to travel along with them, as well as the diffusion of oxygen and nutrients? Authors: The diameter of these dissolving PGF fibres is around $40 \mu \mathrm{m}$, which does fall into the range of a newly forming vascular network. As this parameter can be modified by altering the diameter of the PGF fibres, different vascular networks can be formed dependent upon 


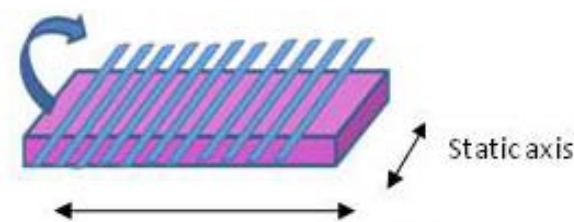

Rolling axis

(a)

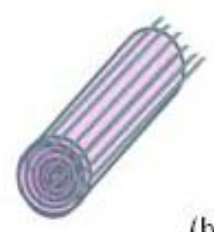

(b)

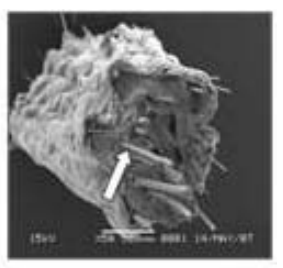

Supplementary Fig. 1. (a) PGF fibres placed onto 3D cell-seeded collagen sheet, and (b) spiralled along the rolling axis, schematic and micrograph. It is only possible to place fibres along the static axis, as they are rigid and therefore will not bend.

the size of tissue engineered construct under development. Of particular importance is the point raised regarding the introduction of endothelial cells (ECs) into these channels. ECs are the primary cell type attracted by angiogenic gradients, particularly VEGF. Our aim is to optimally engineer hypoxia in $3 \mathrm{D}$ constructs, and as the fibres dissolve, ECs be introduced (possibly by means of a rolling bioreactor system), which will preferentially travel to line the channel walls. As ECs are quite resistant to hypoxia, it may be further possible to continue the entire construct (even with continuous channels) under physiological hypoxia to maintain hypoxia-induced signalling by cells seeded in the collagen to continue to attract ECs.

\section{Additional Reference}

Hadjipanayi E, Brown RA, Mudera V, Deng D, Liu W, Cheema U (2010) Controlling physiological angiogenesis by hypoxia-induced signaling. J Control Release 146: 309317. 